\title{
Reorientación productiva de los migrantes: el caso de Santiago Matatlán, Oaxaca
}

\author{
Maricela Ríos \\ Arun Kumar Acharya
}

Resumen. El estudio de la migración se ha centrado en la salida o pérdida de personas de una región y la posterior «recuperación de dinero». Sin embargo, la migración rural se practica, generalmente, bajo una estructura «circular», con la característica principal de una transmisión constante de conocimientos, habilidades, tecnología y recursos humanos y económicos. Entendida de esta manera, es posible concebir la migración como una herramienta con la que se actualizan los elementos culturales que permiten la innovación de los procesos productivos tradicionales y no solamente como una práctica de sobrevivencia económica. Así, en algunas ocasiones, con los retornos de los migrantes se pueden generar cambios socioculturales y productivos que detonan el desarrollo local de su comunidad. Palabras clave: migración, campesinos indígenas, circulación de cerebros, sistemas productivos tradicionales, innovación de procesos productivos.

\begin{abstract}
Migration studies have commonly focused on regional emigration or depopulation and the subsequent «financial recovery». However, rural migration is usually practiced in a «circular» manner, with the main feature being a constant transmission of knowledge, skills, technology and human and economic resources. Seen this way rather than as a mere practice of economic survival, migration can be a tool through which cultural elements that allow for innovation in traditional production processes are updated. Thus and on occasions, migrant return can lead to productive and socio-cultural changes that trigger local communal development. This paper examines four cases of Oaxacan migrant mezcal producers and their experiences, especially in regards to the use of new technologies geared toward mezcal production and commercialization.

KEYWORDS: migration, indigenous peasants, brain circulation, traditional production systems, innovation in production processes.
\end{abstract}

Maricela Ríos es alumna de Doctorado en Ciencias Sociales con orientación en Desarrollo Sustentable, Instituto de Investigaciones Sociales, Universidad Autónoma de Nuevo León.

Arun Kumar Acharya es investigador del Instituto de Investigaciones Sociales.E-mail: acharya_77@yahoo.com. 


\section{INTRODUCCIÓN}

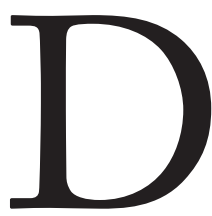

urante las últimas tres décadas, la migración mundial ha aumentado de manera significativa, al pasar de 99.3 millones de personas en 1980 a 214 millones de personas en 2010. Esta última cifra representa $3 \%$ de la población mundial (División de Estadísticas de las Naciones Unidas, 2010). ${ }^{1}$ Las cifras sobre la migración mexicana a Estados Unidos exponen, por sí mismas, la realidad de este fenómeno: de 1980 a 2009 la población nacida en México y residente en Estados Unidos estuvo cerca de sextuplicarse al pasar de 2.1 a 11.5 millones de migrantes documentados e indocumentados (Conapo, 2009). La migración no involucra únicamente la movilización de personas, sino también la de los recursos económicos, conocimientos y habilidades. En este contexto, México captó 21.1 mil millones de dólares en 2009 (15.74\% menos que en 2008 debido a la crisis económica de Estados Unidos); sin embargo, ese mismo año ocupó el tercer puesto a nivel mundial por el concepto de captación de remesas, concentrando 5.4\%, sólo por debajo de India y China.

La influencia de las remesas en el producto interno bruto (Рів) de México ha ido en aumento, ya que 2008 representaron cerca de 3\% del PIB, lo cual significó más de $8.8 \%$ de las exportaciones de mercancías, más del $55 \%$ de las exportaciones petroleras, $135 \%$ de la inversión extranjera directa (IED) y 189\% de los ingresos de viajeros internacionales, colocándose así como la primera fuente de divisas del país (Reyes, 2010). En los estados de Michoacán, Zacatecas, Oaxaca, Guerrero e Hidalgo (entidades con alto nivel de población rural), las remesas de los migrantes han representado más de $10 \%$ del PIв estatal.

11/ Según datos de esta división, en 2005 la población mundial ascendió a 6515 millones de personas. 
A través del intercambio de valores económicos, culturales y productivos, la migración rural ha fortalecido la dinámica comunitaria y la ha sensibilizado hacia la dinámica económica del mercado. Por otro lado, la participación de emigrantes mexicanos en la actividad productiva agrícola - considerada tradicional entre los emigrantes rurales- ha disminuido notablemente (de un 12\% de participación en el sector primario en los años noventa al 4.9\% en 2008) (Conapo, 2009), orientándose hacia otros sectores productivos más especializados, como el de la construcción y los servicios. Esta situación refleja el cambio cultural y de visión productiva que se está gestando entre los migrantes rurales mexicanos, susceptibles al aprendizaje de nuevos oficios, al manejo de maquinaria y tecnología de avanzada. A través de sus experiencias de trabajo, obtienen nuevos valores productivos, al tiempo que se hacen sensibles a los efectos de la globalización en los canales de comercialización, comunicación e información mundial, y no sólo esto, sino que adquieren el conocimiento de un nuevo idioma y con éste se apropian, entre otras cosas, de nuevos simbolismos culturales.

Dado lo anterior, el presente trabajo pretende, por un lado, contribuir a la generación de elementos que propicien nuevas reflexiones teórico-metodológicas sobre el fenómeno migratorio y, por otro, generar información que permita conocer las implicaciones de la migración como catalizador en el cambio del comportamiento productivo del migrante rural mexicano, a partir del estudio de caso de cuatro experiencias migratorias.

\section{¿CÓMO ENTENDER LA MigRACióN?}

Ante la pregunta ¿̇quiénes son los que se van?, Mercedes Arce (2003) responde que las personas que se arriesgan a emprender este tipo de acción son, en general, más emprendedoras y poseen atributos que, de ser apoyados por políticas públicas legítimamente dirigidas a mejorar sus condiciones y capacidades, se podrían convertir en agentes útiles para el desarrollo de ambas 
sociedades. De acuerdo con esto, e independientemente del nivel socioeconómico y educativo del migrante, aquél que decide emigrar cuenta ya con características de personalidad adecuadas al desarrollo.

Ante el flujo de salida de personas de un país hacia otro, se han dado diferentes posturas de análisis; de éstas nos interesa, especialmente, aquélla que estudia la «fuga de cerebros». Esta postura analiza la salida de personal altamente calificado hacia un país que ofrece mejores o mayores oportunidades de desarrollo y crecimiento económico y profesional; sin embargo, no es la única perspectiva teórica que ha buscado explicar el fenómeno migratorio. Baldwin (citado por Casey, Mahroom, Ducatel y Barré, 2001) analiza la «sobreproducción de cerebros» (brain overflow); Allan Findlay (citado por Casey et al., 2001), el «retorno de cerebros» (brain return), el «intercambio de cerebros» (brain exchange) y, entre otras perspectivas, la «circulación de cerebros» (brain circulation). Tal diversidad de términos parece estar ocasionando mayores confusiones que soluciones, ya que unos hablan de fugas y pérdidas mientras que otros están convencidos en darle la mención de circulaciones y ganancias (Teferra, 2005).

Ahora bien, la migración rural difícilmente se ve asociada con los fenómenos migratorios en los que se involucra el intercambio de «altos conocimientos». De cualquier manera, es necesario reconocer que esta práctica no sólo involucra el flujo continuo y cerrado de «altos conocimientos», sino también el de recursos económicos, simbolismos, habilidades y tecnologías, flujos con los que la práctica migratoria es dotada como una fuente de innovación y desarrollo para las comunidades tradicionales que la llevan a cabo. Es así que la migración rural adopta una forma circular que las redes sociales implicadas se encargan de cerrar y, además, de dar continuidad al flujo de intercambio de conocimiento.

Para Casey et al. (2001), el término «circulación de cerebros» es una forma positiva de movilidad que involucra a científicos, investigadores y otros profesionales altamente capacitados que se mueven dentro y fuera de diferentes regiones geográficas y que, por lo tanto, incrementan la difusión 
de su conocimiento. Tomando esta postura como punto de partida, podemos hablar de tres características principales de la migración rural que permiten aplicarle el enfoque de «circulación de cerebros».

a) En ningún momento se considera la salida de personas de un país como una fuga o una pérdida, ya que a través de las redes migratorias se aprovecha la transmisión de conocimientos, habilidades y recursos que el migrante genera en su proceso, lo que hace de la salida un continuo retorno.

b) El término «cerebro» puede ampliarse, de acuerdo con la perspectiva de Giannoccolo (citado por Fazal, 2007), para describir la movilidad de personas con habilidades, conocimientos y atributos aptos para el desarrollo, de manera que la migración rural se concibe integrada a los factores que detonan el desarrollo de las regiones, no sólo por su mano de obra barata (debido en gran medida a su carácter indocumentado) sino también por su capacidad emprendedora e innovadora que, combinada con la infraestructura adecuada, se convierte en una estrategia productiva para ambas regiones.

c) El flujo continuo de transmisión del conocimiento adquirido y de los recursos generados pone en circulación también las ganancias producidas en el proceso migratorio, logrando una notable disminución en los costos asociados al mismo y favoreciendo un entorno de "ganar-ganar» para los países involucrados. En este sentido, el flujo continuo de los conocimientos y recursos generados por los emigrantes rurales es la principal estrategia para el desarrollo de sus comunidades.

El enfoque «cadena migratoria» explica el proceso migratorio como un fenómeno fluido, retroalimentado y circular, y muestra la importancia de las redes sociales para la perpetuación de la migración. Los primeros migrantes son los encargados de generar el conocimiento y las oportunidades que podrán aprovechar aquéllos que les siguen, y así consecutivamente, hasta conformar una compleja estructura de relaciones sociales, culturales, económicas y políticas (MacDonald, 1992). 
Iredale (2005) propuso que el enfoque de «cadena migratoria» sucede en las siguientes tres fases: I) «fuga de cerebros» que ocurre principalmente en los países en vías de desarrollo; 2) asentamiento de los primeros migrantes y creación de condiciones para una nueva «fuga de cerebros», así como para el «retorno de la fuga de cerebros» a muy baja escala, y 3) migración continua, que acentúa la circulación de migrantes y recursos. Esto significa que es en la tercera fase cuando se desarrolla la «circulación» de capital, conocimientos y habilidades.

Durante las últimas dos décadas, se ha iniciado un cambio de perspectiva sobre los efectos de la «circulación de cerebros», ya que se ha observado que la salida de personas altamente calificadas o con habilidades y conocimientos aptos para el desarrollo, también puede tener efectos económicos y sociales positivos para los países de origen (Saxenian, 2002). Así, los países emisores pueden beneficiarse, además de las remesas, de los «efectos de retroalimentación», tales como la transferencia de tecnología e inversiones por las personas capacitadas fuera del país, así como la estimulación indirecta del sector educativo. Estudios recientes muestran que, después de haber adquirido conocimiento específico y adicional en el extranjero, los emigrantes que regresan pueden contribuir de manera significativa al desarrollo del país emisor y salir adelante en él (Breinbauer, 2007).

De esta manera, la migración a entornos más favorables incrementa la innovación global, de manera que las ganancias pueden llegar a fluir de nuevo al país en desarrollo a través del funcionamiento de las redes migrantes y del retorno de los migrantes a sus comunidades. A su llegada, los migrantes que regresan pueden implementar lo aprendido, así como transmitir ideas, actitudes, habilidades y conocimientos que deriven en la innovación dentro de sus sistemas productivos tradicionales (Saxenian, 2005). De este modo, los migrantes se convierten en una fuente de innovación sociocultural y productiva, ubicándose como los actores centrales en el proceso de cambio y desarrollo de una comunidad. 


\section{Santiago Matatlán Oaxaca: COMUNIDAD MIGRANTE}

En algunas zonas rurales mexicanas, la migración —como fenómeno social - forma parte de la estructura identitaria, integrándose en las costumbres comunitarias que orientan su desarrollo sociocultural. En Oaxaca, la población rural representa alrededor de 52\% (Conapo, 2008) y la migración se ha instalado como una práctica sociocultural que ha ido favoreciendo, en algunos casos, el fortalecimiento de sistemas productivos tradicionales. Es el caso, por ejemplo, de la producción de mezcal en Santiago Matatlán. Actualmente, tan sólo en Los Ángeles, California, hay 22 organizaciones pro-migrantes oaxaqueños, lo cual habla de la fuerte vinculación de los migrantes con sus comunidades de origen.

Hablando del caso del mezcal producido en Matatlán, nombre indígena que significa «junto o entre las redes», se compone de los vocablos matlatl, «red», y tlan, «junto a, o entre». El municipio pertenece al distrito de Tlacolula, se fundó en 1575 y se ubica en la región oaxaqueña de los Valles Centrales; cuenta con aproximadamente 9198 habitantes, de los cuales 53\% son mujeres y $47 \%$ son hombres (INEGI, 2005). Su carácter étnico es predominantemente zapoteca y el índice de marginación y migración es «muy alto» $\mathrm{y}$ «alto», respectivamente, lo cual se refleja en las proyecciones realizadas por el Consejo Nacional de Población (Conapo, 2005), donde se muestra que de 9198 habitantes estimados para 2005, habrá tan sólo 5684 habitantes en 2030.

La organización política se basa en los usos y costumbres heredados de la época colonial, aunque se han hecho algunas modificaciones dentro de esta estructura; es el caso del intercambio de personas para el cumplimiento de los deberes cívico-religiosos; con esta modificación se permite que un familiar o amigo pueda realizar a nombre de un migrante los deberes cívicos que le corresponden a éste. De esta manera, no se pierde la continuidad de la tradición y el migrante continúa participando -aunque sea de manera 
indirecta - en las obligaciones comunitarias, pues es él quien se encarga de los gastos. Esta práctica es bien vista por la comunidad y beneficia también a los familiares del migrante.

MAPA I

Localización geográfica de Santiago Matatlán Oaxaca.

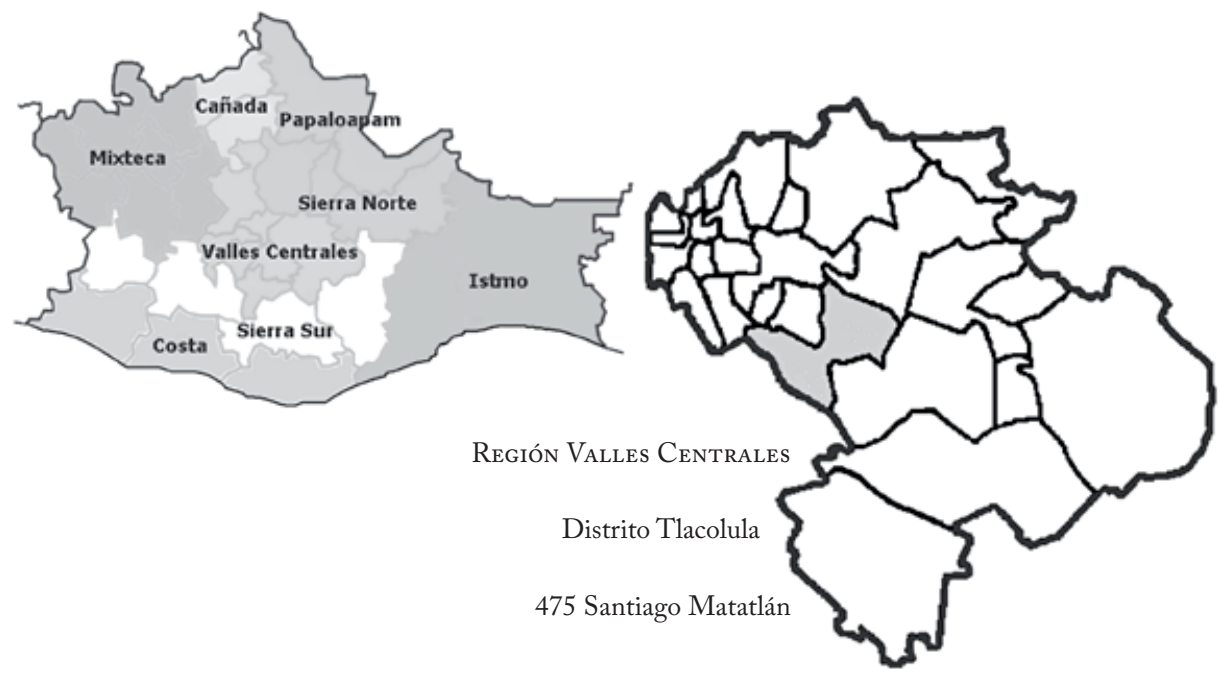

Fuente: INAFED 2008.

La importancia económica del sistema productivo del mezcal en Santiago Matatlán puede manifestarse en el hecho de que aporta más de $90 \%$ de la producción mezcalera estatal, además de que posee aproximadamente $70 \%$ de las fábricas tradicionales estatales de mezcal y $80 \%$ de las marcas comerciales. Del mismo modo, si se toma en cuenta que la actividad manufacturera del estado de Oaxaca representó, en 2009, apenas 1.6\%, la industria tradicional del mezcal retoma importancia no sólo por los ingresos generados (más de cuatro millones de dólares en 2008), sino también por la amplitud del área geográfica que impacta: siete distritos políticos con 131 municipios (23\% del total estatal), 603 localidades y más de 490,745 habitantes (Sánchez, 2005). 


\section{Estudios DE CASO: MIGRACIÓN RURAL Y REORIENTACIÓN PRODUCTIVA}

En este trabajo se presentan cuatro casos de productores de mezcal. Estos casos resultan de algunas entrevistas a profundidad realizadas durante el trabajo de campo de la investigación doctoral titulada «El campesino indígena y la dinámica económica de mercado: implicaciones del conocimiento productivo local del mezcal ante el desarrollo sustentable». A continuación, se presentan las características y experiencia migratoria de los productores.

Productor A: edad, 34 años. Tiene una tradición productiva familiar en la elaboración del mezcal de, al menos, tres generaciones; es el hermano (varón) más chico. Emigró a la edad de 13 años. Sus motivos para irse fueron seguir a su hermano mayor y a tres primos, además de que los costos de transportación y cruce eran accesibles para él y su familia. Se transportó en avión y camión; su punto de cruce fue Tijuana y su destino era la casa de una tía en Santa Mónica, California. Fracasó en su primer intento de cruce y fue deportado. Tuvo que permanecer en Tijuana al menos 15 días en lo que volvía a intentarlo; esa segunda ocasión fue exitosa. La experiencia del cruce fronterizo en palabras del productor:

-P: ¿Y por dónde atravesó?

-R: Pues por aquí en Tijuana, donde le dicen Tecate. En la primera intentada sí nos agarraron. No, sí se siente feo, ¿̇eh?, como perro... Ya íbamos a escapar, pero apareció un helicóptero arriba y nos aventaron unas luces de colores; me acuerdo, ya no podíamos ver ni por dónde correr. Las luces son como...

-P: ¿De bengala?

—R: Ándale, cómo de rayos láser y ahí nos atontamos.

-P: ¿Y con quiénes se fue? 
-R: Fuimos como cuatro; con mi hermano me fui, mi hermano, $\mathrm{y}$ tres primos. $Y$ ya, pues nos agarraron en el primer intento, nos mandaron a la cárcel y de ahí pa'Tijuana de nuevo, hasta que en 15 días se completó el viaje, pero era más fácil antes [...]

Productor A, entrevista personal 20 de marzo de 2009 Santiago Matatlán, Oaxaca

Para el cruce, contrataron un pollero recomendado por familiares; su costo fue de 500 dólares. La estancia en Estados Unidos duró sólo siete meses, en los cuales, por órdenes de su tía, ingresó al high school y trabajó eventualmente en el restaurante del tío. El emigrante no contaba con algún plan u objetivo económico, como él lo expresa:

-P: ¿Cuánto tiempo estuvo allá?

-R: No duré mucho, fui a dar una vuelta nomás; era yo chamaco, no pensaba en dinero, no pensaba en nada del futuro, en nada $[\ldots]$

\section{Productor A}

Lo anterior resulta importante dado que, al no tener un plan económico o un objetivo de desarrollo, la experiencia migratoria no impactó de manera importante en el pensamiento económico del ahora productor, ya que no pudo desarrollar habilidades laborales y económicas que pudiese aplicar posteriormente a su modo tradicional de producir mezcal. Continuando con su relato, comenta que una vez dispuesto a regresar a Santiago Matatlán, acudió con su tía para que lo ayudara con los enlaces y papeleos necesarios para iniciar su regreso a la comunidad, ante lo cual su tía insistió en que se quedara y trabajara nuevamente, pero él prefirió regresar a casa. Cabe destacar que la familia con la que él y su hermano llegaron a Santa Mónica son familiares directos por parte de su mamá. Su tío es uno de los principales productores 
de mezcal en Santiago Matatlán, por lo cual viaja continuamente a Oaxaca y supervisa la producción de su fábrica. Así mismo, es miembro activo de las diversas organizaciones oaxaqueñas de migrantes en California, como la Federación Oaxaqueña de Comunidades y Organizaciones Indígenas en $\mathrm{Ca}-$ lifornia (Focoica), de la cual ya fue presidente, así como de la red conocida como Paisanos Unidos de Matatlán.

A su regreso a Oaxaca, el Productor A culminó sus estudios de secundaria al tiempo que trabajaba en la fábrica de mezcal de su papá, actividad que continuó realizando hasta los 19 años, edad en que se casó. Así, durante ocho años trabajó para varios productores de mezcal, tanto de su comunidad como del municipio de Tlacolula de Matamoros, los cuales le prometieron buenos salarios y mejores condiciones laborales, situación que de una u otra forma no se dio. Por estos elementos y el aumento de necesidades económicas, decidió integrar su propia fábrica y marca de mezcal, para lo cual pidió prestado a familiares (sus tíos de California) el equipo necesario para la elaboración de mezcal, mientras reunía el dinero para comprar los propios a través de su trabajo como jornalero.

El Productor $A$ refirió haber observado el éxito de otros productores de mezcal que, como él, no contaban con ningún recurso económico adicional, pero que gracias a que emigraron pudieron reunir cierta cantidad de dinero, así como nuevos conocimientos y perspectivas de desarrollo productivo del mezcal. Con el tiempo, el Productor $A$ ha ido dando a conocer la calidad de su mezcal, con lo que ha tenido oportunidades de negociar contratos de compra a futuro, garantizando así la continuidad de su producción y, sobre todo, la estabilidad económica para sostener a su familia. Recientemente, promovió su producción tradicional del mezcal ante estudiantes alemanes de gastronomía, mismos que grabaron un documental sobre su proceso productivo en su fábrica. Actualmente, se encuentra tramitando el nombre de su marca.

Productor B: edad, 52 años. Cuenta con una tradición de más de tres generaciones en la producción de mezcal y siembra de maguey. Trabajaba en el 
campo desde muy pequeño, ayudando a su papá en la siembra del maguey y pastoreando chivos; posteriormente, empezó a movilizarse a la ciudad buscando mayores ingresos y otro tipo de trabajo. En palabras del productor:

-P: ¿Y a qué se debió que se animara a sacar su marca?

—R: Si yo le platicara mi vida... Empecé vendiendo periódicos, paletas en las tardes; por aquel entonces iba yo a bolear zapatos al cine Mitla. Estudié la primaria en la escuela de adultos, ahí logré terminar mi primaria; eso me ayudó bastante. En aquel entonces yo crecí y viví en un rancho, y a los nueve años ya quería ver que seguía de ahí $[\ldots]$

\section{Productor B, entrevista personal 4 de abril de 2009 Santiago Matatlán, Oaxaca}

Conforme fue creciendo, al Productor B se le presentó la oportunidad de trabajar como maestro instructor en la escuela de adultos, pero esa labor no lo convenció del todo y declinó la oferta. Él sabía que había nacido para la producción de mezcal, pero aun así dejó la producción mezcalera de su papá y, junto con amigos y miembros de la comunidad, se fue a trabajar al «norte» (Estados Unidos) a la edad de 18 años. Se movilizaron en tren y camión, utilizaron al pollero que la mayoría de la comunidad empleaba para el cruce y llegaron a California. Consiguieron trabajo en un rancho cerca de San Diego gracias a emigrantes matatecos ya establecidos. En sus palabras:

- Hubo la oportunidad de trabajar como maestro instructor, pero no me gustó y dije: «y ahora sí, qué voy a hacer». Porque con esto —el mezcal— sentía que tengo un toque, pero yo quería ver, seguir. Ya de ahí que me entra la locura de ir a trabajar al norte y de ahí aprendí; bueno, de hecho me di cuenta por qué ellos son productivos y cuál es la diferencia de que ellos puedan... 
Claro que no hay igualdad entre Matatlán y Estados Unidos; por lo menos hay que tratar de cambiar un poquito y pues tuve la suerte de llevarme bien con mi patrón, y hacía yo de cuenta que ahí tenía yo otra familia pues, y hubo la oportunidad de meter los papeles para legalizarme, pero ora sí que los papeles estaban en trámite cuando me vine para acá.

-P: ¿YY por qué se regresó?

-R: Lo que pasa es que estaba yo ahí cuando se murió mi papá, y pues la locura, ora sí dejé todo así y me vine. Según yo, iba a regresar como en una semana y ya no regresé [...]

Productor B

El Productor B permaneció casi cinco años en Estados Unidos, aprendió el idioma y el manejo de maquinaria agroindustrial, ya que en el rancho donde trabajaba se producía manzana que era empaquetada para su venta. Inició trabajando como jornalero; debido a que aprendió rápido el idioma y a que tenía habilidades de liderazgo, el dueño del rancho lo cobijó y le ofreció el puesto de capataz. Al año y medio ya era el jefe de todos los jornaleros y controlaba la producción de manzana; mientras, aprendía sobre el proceso mecanizado. Debido a sus capacidades para el control del personal y al entendimiento de los estándares de calidad, el dueño del rancho buscó la manera de tramitar su residencia oficial en Estados Unidos. Durante su estancia en Estados Unidos, el Productor B enviaba 100 dólares a su familia cada dos meses, llegando a incrementar la cantidad a 300 ó 500 dólares. Ocasionalmente, pudo enviar dinero para actividades comunitarias y realizó un ahorro personal. Ya de regreso en Matatlán, y dándose cuenta que regresar a Estados Unidos iba a ser más difícil, buscó una manera de empezar a generar dinero, ya que veía cómo sus ahorros se iban agotando. Él lo expresa así:

—R: El dinero se va como agua... ¿Qué voy a hacer? Y pensé que de lo poquito que había ahorrado tenía que invertirlo en algo, si 
no cuando me diera cuenta ya no iba a tener ni un quinto. Lo primero que empecé a hacer fue sembrar maguey en los terrenos que me había dejado mi papá y eso fue lo que me ayudó.

-P: ¿Usted ya sabía sembrar el maguey?

-R: Sí, pues como eso era el trabajo de mi papá, ya no era novedad para mí, porque yo lo ayudaba de niño, y pues así fue, empecé poco a poco. Comencé a trabajar en fábricas de mezcal rentadas, $y$ fue un rato el que le estuve entregando mezcal a las grandes empresas de Matatlán y Tlacolula, casi a todos los envasadores. Pero el problema es quedarse con uno aparte, tener uno su propia fábrica. Y ahora sí que a todos los terrenos les metía yo maguey, entonces eso fue lo que me ayudó, porque hubo momentos en los que ya no tenía que comprar maguey para sacar la producción de mezcal, nada más cortaba de mi propio maguey. Y ya de ahí fue que me entró la idea de sacar mi propia marca, pero digamos que esto lo fui haciendo como jugando nada más, para ver qué pasaba. Hablé con otros productores de mezcal que vendían a menudeo y pues vi cómo juntarnos para tener una sola marca, y ya ahorita pues gracias a Dios está saliendo. De repente llegan pediditos de mezcal... pedidos pequeños, pero llegan; nosotros estamos trabajando los 365 días del año, los demás trabajan por temporadas, y ahorita lo que estamos haciendo es también almacenar $[\ldots]$

\section{Productor B}

De este modo, al regreso buscó invertir su dinero en la actividad que ya dominaba y conocía desde niño, la elaboración de mezcal y siembra de maguey. Aplicando los conocimientos, habilidades y prácticas desarrolladas en Estados Unidos, pudo abrirse paso entre los productores tradicionales y cumplir su objetivo de ahorrar para construir una fábrica con equipo modernizado; esto le permitió producir un mezcal que cumpliera con las normas de 
calidad del mercado. Asimismo, pensó en organizar a los productores aislados y constituyó una sociedad de producción rural con más de 30 integrantes, de la cual él es el presidente y representante legal y comercial. Actualmente, cuenta con una marca registrada de mezcal y con la certificación de producción orgánica nacional e internacional. Así mismo, ha iniciado la exportación de su mezcal a Guatemala y Canadá. El Productor B participa activamente en la toma de decisiones comerciales y de calidad en la industria nacional y estatal del mezcal, y asiste a diversas ferias nacionales e internacionales para promover su producto. Además, el conocimiento del inglés le ha abierto muchas puertas comerciales.

Productor c: edad, 33 años. Viene de dos generaciones productoras de maguey y mezcal. A los 22 años, emigró junto con unos amigos. En su viaje a la frontera, hizo una breve escala en Ciudad Netzahualcóyotl, Estado de México, donde estuvo viviendo con familiares por un periodo de seis meses, durante los cuales trabajó en el comercio informal para ahorrar y pagarle al pollero. Ya en Tecate, tuvo que esperar 15 días para «cruzar», debido a que la Patrulla Fronteriza había iniciado un nuevo esquema de vigilancia, por lo que el pollero les cobró 100 dólares más, teniendo que pagar 750 dólares. En total, cruzaron 12 personas, de los cuales cinco eran oaxaqueños (tres matatecos y dos mixtecos), el resto era de otros estados de la República Mexicana. Llegó a casa de amigos, los cuales ya le tenían listo un trabajo.

El Productor $C$ venía de dedicarse a las faenas del campo y a la producción de mezcal en Oaxaca, pero en Los Ángeles lo esperaba un cambio laboral: la construcción. Estuvo trabajando por cuatro años para la constructora de un mexicano nacido en Estados Unidos. En las épocas que no había contratos, trabajaba en el área de servicios, pintando casas, arreglando jardines e incluso en una panadería local. Envió remesas mensuales a su familia para el gasto diario y en una ocasión pudo escapar de una redada, pero dos de sus amigos no; eso lo puso a pensar en lo que esperaba de su estadía en Estados Unidos. Un compañero le ofreció que se fuera con él a Chicago, donde había 
otra comunidad grande de oaxaqueños, pero el Productor c prefirió quedarse en Los Ángeles.

De esta manera, después de cuatro años de trabajar en la construcción y juntar suficiente dinero para pagar su regreso y poder invertir sus ahorros en algo, regresó a Matatlán, motivado principalmente por la posibilidad de volver a estar con su familia y de trabajar en lo suyo. Ya en Matatlán, el productor abandonó la siembra del maguey y producción del mezcal por considerarla muy lenta y mal pagada. Adquirió un camión de redilas para dedicarse a la siembra y comercialización de maíz, frijol y calabaza, ya que en esa actividad la producción era más corta y la movilidad del producto era mayor, lo cual le daba más trabajo y más dinero. Al preguntarle por qué no buscaba trabajo en las constructoras ubicadas en la capital del estado, señaló que casi no había trabajo y que, además, pagan muy mal, que las jornadas eran muy pesadas y el equipo muy malo, que prefería trabajar el campo a su ritmo y con su propio equipo, además que ya tenía idea de cómo vender su producto. Por otro lado, al preguntarle por qué no retomó la actividad productiva del mezcal, el productor contestó lo siguiente:

-R: Ahora me dedico al campo, siembro milpa por el rancho Zapata, en Mitla.

-P: ¿Y dónde lo vende?

-R: Aquí en el pueblo; en Tlacolula vendo también el elote y el zacate verde.

-P: ¿Y por qué no pensó en regresar al mezcal?

-R: Pues, la verdad, porque últimamente bajó mucho el mezcal; ya no había venta, no hay salida del producto, pues. Además de que es mucha inversión; incluso si tienes dinero guardado, pues de dónde, ya se me hizo difícil todo, entonces cancelé la fábrica y me dediqué al campo

-P: ¿Y no pensó en rentar su palenque?

-R: Bueno, de hecho el equipo ahorita lo tiene mi otro herma- 
no, que también tiene fábrica, y éste se llevó la olla, el equipo; de hecho, me dice que cuando yo quiera puedo ir a sacar mezcal [...]

Productor c, entrevista personal 16 de abril de 2009 Santiago Matatlán, Oaxaca

Actualmente, el productor continúa en la actividad del campo y trabaja como jornalero para otros productores; asimismo, apoya con trabajo y equipo a familiares y amigos en la producción de mezcal. Además, tiene pensado adquirir un tractor. Está por terminar de construir su propia casa, ya que a los dos años de regresar de Los Ángeles se casó y tiene un niño de cuatro años.

Productor D: edad, 39 años. Viene de tres generaciones dedicadas a la producción de maguey y mezcal. Emigró a la edad de 17 años, cruzando por Tijuana. El motivo para irse fue que en 1988 había muchos matatecos que estaban saliendo del país y un conocido que había emigrado le comentó las oportunidades de vivir en Estados Unidos, así que se animó y se fue con otros miembros de la comunidad. Llegaron a Los Ángeles y residentes oaxaqueños les ayudaron a conseguir dónde vivir y rentaron un departamento entre seis matatecos. Asistió a las reuniones de las asociaciones de migrantes oaxaqueños y fue conociendo las experiencias de sus paisanos.

Uno de los emigrantes que cruzó con él lo ayudó a conseguir trabajo; es así que estuvo de lavaplatos en un restaurante por dos años, aproximadamente. Al mismo tiempo, trató infructuosamente de ingresar al high school, por lo que se inscribió en un curso de inglés en el que estaba en contacto con más emigrantes. Narra que de los compañeros que más se acuerda eran un chino y un japonés, ya que había entablado con ellos un tipo de competencia por ver quién aprendía y dominaba más rápidamente el idioma. Menciona que el trabajo en restaurante era pesado, tenía un chef francés muy exigente, que no los dejaba comer, sentarse o ir al baño en horario de trabajo. En palabras del productor: 
La pasé muy feo en el restaurante, porque había un chef francés que no te dejaba comer, sentarte o ir al baño, pero bueno, yo creo que hasta cierto punto estaba bien, yo lo tomé de manera positiva porque de esa manera aprendí también, me discipliné y aprendí a trabajar cuando se tiene que trabajar [...]

Productor D, entrevista personal 15 de julio de 2009 Santiago Matatlán, Oaxaca

De esta manera, cuando se cuestionó al Productor D sobre lo que había aprendido en su experiencia migratoria, contestó:

Yo creo que me dio un poco más de visión, porque cuando estás en tu lugar, muchas veces no sabes qué pasa, pero cuando vas afuera, cuando te sales, ya tienes un poco más de visión, ya puedes pensar diferente, eres más abierto, más comunicativo con la gente. Aprendí inglés, aprendí muchas cosas, valoré más mi idioma, valoré mi casa, mi familia, mi identidad, porque siento que en Estados Unidos no hay cultura, no hay raíces. Aquí sabemos de dónde venimos y a dónde vamos, allá no [...]

Productor D

En su estancia en Los Ángeles cambió dos veces de trabajo, pero siempre manteniéndose en el área de servicios, hasta que enfermó; al no tener quién lo atendiera, decidió regresar a Santiago Matatlán. Después de más de tres años, el Productor D regresó a su comunidad para recuperarse. Aunque había considerado firmemente regresar a Estados Unidos, dado que había dejado trabajo, amigos y quería regresar a la escuela, una vez recuperado comenzó a integrarse en la dinámica de la comunidad, en el trabajo cotidiano del palenque, trabajando en las casas de otras personas y como vocalista de un grupo musical. 
Fue hasta sus 24 años que se casó y finalmente decidió dedicarse por completo a la producción y venta del mezcal. Consideró que la actividad mezcalera le podría dar mayor estabilidad económica, así como un estatus dentro de su comunidad. De este modo, el Productor D renta un local a su madrina y abre un punto de venta para su mezcal. Al cuestionarlo sobre su elección laboral en Estados Unidos, él mencionó:

Cuando llegué a Estados Unidos, no quise trabajar en el campo, claro porque de tanto haber ido al campo desde niño pues ya como que uno se cansa, yo antes cuidaba rebaños. Por eso opté por un trabajo más fácil, porque el campo es más duro, es para trabajar, pero yo no soy de los que agarran la barreta, yo soy de los que piensa qué puedo hacer, o vender, yo quiero hacer cosas [...]

Productor D

En 1997 registró la marca de su mezcal y compró un terreno que le ha brindado la oportunidad de acercarse al mercado para instalar su fábrica. Certificó su producto para tener acceso total al mercado y buscó la diversificación a través de la elaboración de «cremas» de mezcal. Debido a que manejó equipo de cómputo y venta por internet en el restaurante donde trabajó en Estados Unidos, buscó la manera de crear una página web para dar a conocer su producto a nivel mundial. Actualmente, ha hecho promoción a su mezcal en ferias nacionales e internacionales y cuenta con una participación muy activa en la toma de decisiones comerciales y de calidad de la industria mezcalera, llegando a tener cargos directivos en el Patronato Oaxaqueño del Mezcal.

\section{Conclusiones}

Cuando se menciona el término migración es común que la gente asocie tanto la movilización de personas como la de recursos económicos; sin em- 
bargo, son pocas las veces que se identifica también la transmisión de conocimientos, experiencias, habilidades, tecnologías y, sobre todo, el cambio generado a nivel de representaciones, simbolismos e identidad. Por ello, resulta primordial para países subdesarrollados como México (cuya práctica migratoria se da mayormente entre la población rural) estudiar los efectos que la migración genera en la estructura sociocultural y productiva de las comunidades rurales, las cuales podrían convertirse en catalizadoras de un desarrollo regional basado en la innovación y actualización de los sistemas productivos tradicionales, logrando con esto que la práctica de la migración pueda ser una fuente no sólo de recursos económicos para la comunidad, sino también una herramienta que permita establecer y generar un cambio en la racionalidad económica de los pobladores rurales.

Dado lo anterior, deberían establecerse políticas de inclusión productiva de los migrantes que regresan a sus comunidades, desarrollar conjuntamente con ellos proyectos productivos que exploten y aprovechen todo el conocimiento, habilidades y técnicas desarrolladas en su experiencia migratoria, y que les permita, por un lado, fortalecer la estructura económica de su comunidad y, por otro, desarrollarse como agentes de cambio. En este sentido, en la investigación realizada se pudo constatar que los productores que migraron comparten algunas características de personalidad: son individuos extrovertidos, emprendedores, asumen riesgos y retos, les gusta la competitividad y el trabajo continuo, están dispuestos a aprender cosas nuevas e innovar sus procesos.

En los cuatro estudios de caso, durante el tiempo que estuvieron fuera, así como al momento del regreso a la comunidad y de la reintegración a la misma, existió una transmisión continua de conocimientos y recursos a través de las redes sociales previamente formadas por otros migrantes y familiares, mismas que facilitaron en cierta forma el éxito de su experiencia migratoria. En este sentido, la migración «circular» que practica la mayoría de los pobladores rurales en México fomenta en algunos casos la reorientación del pensamiento productivo tradicional hacia lo moderno y hacia el mer- 
cado global. Lo importante de esto es que, al estar expuesto a condiciones socioculturales, tecnológicas y económicas totalmente diferentes, el propio productor tradicional va desarrollando (en algunos casos) nuevos esquemas mentales que le permiten reinterpretar su realidad comunitaria y buscar así nuevas alternativas de desarrollo. Por lo mismo, debiese resultar vital para el Estado poder captar a la mayor cantidad de migrantes que regresan a sus comunidades y auxiliarlos en su integración productiva, ya que dentro de ese proceso se pueden obtener resultados positivos para el desarrollo local.

Analizando los casos, se tiene que las características de la experiencia migratoria del Productor $A$ generaron una menor influencia en el cambio sociocultural y productivo hacia una dinámica orientada al mercado. Parece ser que la brevedad de su estancia en Estados Unidos, su corta edad y la falta de un objetivo por el cual migrar incrementaron su resistencia al cambio y fortalecieron, por otro lado, el peso de la tradición productiva. Sin embargo, gracias a que emigró pudo sensibilizarse en cuanto a la importancia de la educación, del valor de su identidad cultural y productiva; asimismo, le sirvió para integrarse a redes sociales externas que posteriormente utilizó para desarrollar su actividad productiva, aunque la desarrollara todavía de manera tradicional. Actualmente, la producción del Productor A empieza a orientarse poco a poco hacia la lógica comercial, basada en el cumplimiento de estándares de calidad y en el ingreso formal al Consejo Mexicano Regulador de la Calidad del Mezcal.

Del mismo modo, se observa un fortalecimiento de su identidad productiva, aprovechando la tradición como un valor agregado de su producto (actualmente promueve una variedad de mezcal que se considera típico de la región de Santiago Matatlán, el mezcal de pechuga de pollo). Fomenta profundamente su actividad productiva en sus hijos, integrándolos a la dinámica de la producción: desde la siembra y el cuidado del maguey hasta el destilado y el envasado de mezcal. Considera también que la educación escolar es clave para el desarrollo social y económico de sus hijos. Cabe señalar que 2010 fue un año muy duro para este productor, ya que su hijo menor de ocho años 
falleció en un accidente dentro de una fiesta y esto cimbró fuertemente sus deseos de continuar con su actividad productiva, pues su hijo colaboraba con él todos los días después de regresar de la escuela. No obstante, participó en la feria de mezcal celebrada en Santiago Matatlán y ha establecido un contrato con un intermediario que promueve su producto en los restaurantes y bares de la ciudad de Oaxaca.

En cuanto al Productor B, la experiencia migratoria determinó por completo su estructura sociocultural, generando cambios importantes en su actividad productiva, especialmente el haber aprendido y desarrollado habilidades de liderazgo y de organización de la producción y comercialización, lo cual lo sensibilizó profundamente hacia el empleo de tecnología y maquinaria moderna en la producción de mezcal. Por otra parte, el manejo de otro idioma le ha permitido ampliar sus estrategias comerciales. De este modo, su nueva visión productiva y capacidad de liderazgo le permitió unificar a más de 30 productores y conformar una sola empresa, misma que él controla. Así, su experiencia migratoria se convirtió en una herramienta para el desarrollo comunitario de Matatlán, además de convertirlo en un agente de cambio que fortalece la sustentabilidad de la actividad productiva del mezcal.

La experiencia migratoria del Productor $C$ aporta nuevos elementos en cuanto a la reorientación de la actividad productiva, puesto que antes de emigrar su actividad productiva principal era la producción de mezcal, pero a su regreso fue la producción y comercialización de maíz, frijol y calabaza en los mercados locales y regionales. Este cambio en la actividad productiva podría explicarse porque durante su estancia en Estados Unidos desarrolló trabajos que lo pusieron en contacto con mejores niveles salariales; muy probablemente, lo acostumbraron también a una actividad productiva más dinámica, donde el trabajo y el salario tenían un ciclo más corto que el establecido en la actividad tradicional de mezcal. De esta manera, se puede apreciar que no toda la experiencia migratoria resalta y fortalece exclusivamente las tradiciones productivas comunitarias, sino que en algunos casos las debilita (disminuyendo el número de productores que se dedican a ella), pero crea 
o fortalece el surgimiento de nuevas prácticas productivas que implican un mayor dinamismo económico a favor de la comunidad. Cabe destacar que el Productor $C$ tiene contempladas mejoras en su equipo de trabajo y en las herramientas, mismas que le permitirán ampliar su participación en el mercado de productos primarios.

Para el Productor D la experiencia migratoria cambió su visión sociocultural y laboral, pues se probó a sí mismo trabajando en actividades ajenas al campo, desempeñándose de buena manera. Su aprendizaje del idioma inglés le abrió las puertas para ascender en su trabajo y adquirir nuevos conocimientos y habilidades en cuanto al manejo de personal, atención al cliente, la importancia de la disciplina laboral y el cumplimiento de normas, así como la efectividad de la diversificación del producto y de los canales de comercialización. A su regreso, se dedicó a otras actividades productivas ajenas a la producción de mezcal; sin embargo, cuando requirió una mayor estabilidad económica optó por la elaboración de mezcal (dado que era la actividad que dominaba tanto él como su familia), donde pudo implementar y aprovechar todo lo aprendido. Su liderazgo, actitud emprendedora y visión moderna de su actividad facilitaron su paso y diferenciación entre los productores locales, haciéndolo protagonista y agente de cambio en la dinámica mezcalera oaxaqueña.

Dado lo anterior, puede decirse que la migración — como fenómeno social- es fuente inagotable de transmisión de recursos humanos, económicos, tecnológicos y que, sobre todo, siembra en los migrantes rurales (y no sólo en ellos) los elementos necesarios para gestar un cambio sociocultural y productivo. En algunos casos, logra desarrollar agentes de cambio que actualizan las estructuras socioculturales e inyectan dinamismo, innovación y modernidad a las estructuras tradicionales productivas, acercándolas poco a poco a una dinámica de mercado que retribuya mejor su trabajo. Sin embargo, resulta indispensable vincular estos nuevos conocimientos y habilidades, así como este cambio de visión, con oportunidades reales para el desarrollo comunitario productivo; sólo así se estaría gestando una estrategia de desarrollo comunitario sustentable a partir de la migración. 


\section{REFERENCIAS}

Agrawal, Ajay, Devesh Kapur y John McHale (2008), «Brain Drain or Brain Bank? The Impact of Skilled Emigration on Poor-Country Innovation», NBER Working paper núm. 14592, Massachusetts, National Bureau of Economic Research.

Arce, Mercedes (2003), «Migración latinoamericana y sostenibilidad: una reflexión inconclusa», Revista trimestral latinoamericana y caribeña de desarrollo sustentable, vol. I, núm. 2.

Breinbauer, Andreas (2007), «Brain Drain-Brain Circulation or \&What Else Happens or Should Happen to the Brains? Some Aspects of Qualified Person Mobility /Migration», FIW Working Paper, núm. 004, Berlín, FIw.

Casey, Tom, Sami Mahroom, Ken Ducatel y Remi Barré (editores) (2001), The mobility of academic researchers: academic careers and recruitment in ICT and biotechnology, Sevilla, Institute for Prospective Technological Studies. Conapo (2009), Estadísticas poblacionales México, México, Conapo, disponible en «www.conapo.gob.mx».

De HaAs, Hein (2008), «The internal dynamics of migration processes», IMSCOE Conference on Theories of Migration and Social Change, Oxford, St Anne's College, University of Oxford.

De los Ríos, Juan y Carlos Rueda (2005), «Fuga de cerebros en el Perú: sacando a flote el capital hundido», Economía y Sociedad, núm. 58.

División de Población de la Organización de las Naciones Unidas (2010), Estadísticas de la población mundial, Nueva York, onu.

FAZAL, Rizvi (2007), «Brain drain and the potential of professional diasporic networks», en Lesley Farrell y Tara Fenwick (editores), World Yearbook of education 2007: educating the global workforce. Knowledge, knowledge work, and knowledge workers, Nueva York, Routledge.

inafed (2008), Municipio Santiago Matatlán, consulta electrónica: «www. inafed.gob.mx> $(6 / 12 / 2010)$. 
inegi (2005), II Conteo de Población y Vivienda, Aguascalientes, inegi. International Organization of Migration (IOM) (2003), World Migration Report 2003: Managing Migration-Challenges and Responses for People on the Move, vol. 2, Ginebra, Iom.

Iredale, Robyn (2005), «Balancing the Benefits and Costs of Skilled Migration in the Asia-Pacific Region», en Irena Omelaniuk (editor), World Migration: Costs and Benefits of International Migration, vol. 3, World Migration Report Series, Ginebra, IOM.

LEe, Everett (1966), «A Theory of Migration», Demography, vol. 3, núm. 1. MacDonald, John Stuart (1992), «Chain migration reconsidered», Bolletino de Demografía Storica, núm. 16.

MacDonald, John Stuart y L. D. MacDonald (1964), «Chain Migration Ethnic Neighborhood Formation and Social Networks», The Milbank Memorial Fund Quarterly, vol. 42, núm. 1.

Massey, Douglas et al. (2003), «Theories of International Migration: A Review and Appraisal», Population and Development Revierw, vol. 19, núm. 3.

Reyes, Tepach (2010), «La captación del flujo de remesas en México para el periodo enero-diciembre, 2007-2009», México, LXi Legislatura Cámara de Diputados.

SÁnchez López, Alberto (2005), Oaxaca, tierra de maguey y mezcal, Oaxaca, Conacyt, Fundación Produce Oaxaca, Secretaría de Educación Pública. Saxenian, AnnaLee (2005), «From Brain Drain to Brain Circulation: Transnational Communities and Regional Upgrading in India and China», Studies in Comparative International Development, vol. 20, núm. 2. (2002), «Brain Circulation: How High-Skill Immigration Makes Everyone Better Off», The Brookings Review, vol. 20, núm. 1.

Tannock, Stuart (2007), «Beyond national borders reframing global brain drain debate», Cardiff University, núm. 73.

Tefferra, Damtew (2005), «Brain Circulation: Unparalleled Opportunities, Underlying Challenges, and Outmoded Presumptions», Journal of Studies in International Education, vol. 9, núm. 3. 